\title{
Evaluation of Energy in Heated Water Vapor for the Application of Lung Volume Reduction in Patients with Severe Emphysema
}

\author{
Erik Henne $^{a}$ Steven Kesten ${ }^{a}$ Felix J.F. Herth ${ }^{b}$ \\ a Uptake Medical Corp., Tustin, Calif., USA; b Pneumology and Critical Care Medicine, Thoraxklinik Heidelberg, \\ Heidelberg, Germany
}

\section{Key Words}

Emphysema · Endoscopic lung volume reduction · Tissue ablation

\begin{abstract}
Background: A method of achieving endoscopic lung volume reduction for emphysema has been developed that utilizes precise amounts of thermal energy in the form of water vapor to ablate lung tissue. Objective: This study evaluates the energy output and implications of the commercial InterVapor system and compares it to the clinical trial system. Methods: Two methods of evaluating the energy output of the vapor systems were used, a direct energy measurement and a quantification of resultant thermal profile in a lung model. Direct measurement of total energy and the component attributable to gas (vapor energy) was performed by condensing vapor in a water bath and measuring the temperature and mass changes. Infrared images of a lung model were taken after vapor delivery. The images were quantified to characterize the thermal profile. Results: The total energy and vapor energy of the InterVapor system was measured at various dose levels and compared to the clinical trial system at a dose of 10.0 $\mathrm{cal} / \mathrm{g}$. An InterVapor dose of $8.5 \mathrm{cal} / \mathrm{g}$ was found to have the most similar vapor energy output with the smallest associated reduction in total energy. This was supported by characterization of the thermal profile in the lung model that
\end{abstract}

demonstrated the profile of InterVapor at $8.5 \mathrm{cal} / \mathrm{g}$ to not exceed the profile of the clinical trial system. Conclusions: Considering both total energy and vapor energy is important during the development of clinical vapor applications. For InterVapor, a closer study of both energy types justified a reduced target vapor-dosing range for lung volume reduction. The clinical implication is a potential improvement for benefiting the risk profile.

Copyright @ 2013 S. Karger AG, Basel

\section{Introduction}

Clinically relevant lung volume reduction can be achieved endoscopically via several techniques. Incremental progress has been achieved over the years with refinement of equipment, technique and, perhaps most importantly, patient selection [1]. Endoscopic approaches can involve the implantation of devices (i.e. valves or coils), the implantation of chemical substances (sealant) or ablation and remodeling (heated water vapor). The application of heated water vapor leads to an initial localized inflammatory response followed by a healing response characterized by contraction fibrosis without evidence of chronic inflammation. Ablation and remodeling reduce lobar volume [2-4].

The output from the thermal ablation system, heated water vapor, is the means to deliver thermal energy to the

\section{KARGER}

E-Mail karger@karger.com

www.karger.com/res
(C) 2013 S. Karger AG, Basel

0025-7931/13/0856-0493\$38.00/0
Erik Henne

Uptake Medical

1173 Warner Ave.

Tustin, CA 92780 (USA)

E-Mail ehenne@uptakemedical.com 
airways and parenchyma. It is the thermal energy within the water vapor that elicits the response [5]. Vapor is a mixture of fine water droplets (liquid) and vapor (gas). The total energy (TE) of the vapor is the sum of the energy contributed by the liquid and gas components of the vapor. The component of the TE due to gas only is referred to as vapor energy (VE). The measured TE delivered per treatment interval has been the primary variable used for vapor dosing; however, both TE and VE have been measured as part of the development program.

Thermal vapor ablation is based on a target range of TE delivered. The target upper limit in clinical trials was $10.0 \mathrm{cal} / \mathrm{g}$ with an acceptable lower limit of $7.5 \mathrm{cal} / \mathrm{g}$. The system obtained regulatory approval for the treatment of severe and very severe emphysema in Europe and Australia based on the clinical results from the 1-year VAPOR trial [2-4]. A second-generation system was developed for widespread postapproval use that had improved energy consistency, usability and manufacturability. We sought to use bench studies to determine if a reduced range of target dosing could be justified, by studying the effects of both TE and VE that might further improve the overall benefit to the risk profile of the system.

\section{Methods}

This report considers two methods of evaluating the energy of vapor, which are used to compare the clinical trial system to the next-generation InterVapor system. The two approaches are: the direct measurement of energy and a lung model enabling assessment of thermal distribution subsequent to delivery of vapor.

\section{TE and VE Measurement}

The TE and VE of vapor systems are characterized using a water bath following a method similar to calorimetry [6]. Vapor is delivered to the water bath, which is large enough to condense all vapor immediately, resulting in a complete transfer of energy to the water bath. TE from a vapor delivery is equal to the change in water bath energy between the initial and final states. This energy change can be calculated from the specific heat capacity of water [7].

$\mathrm{TE}$ of a vapor delivery is calculated in calories, using equation 1 :

$$
T E=\left(m_{w F}+m_{w R}\right) \cdot C_{p, L}\left(T_{F}-T_{R}\right)-m_{w I} \cdot C_{p, L}\left(T_{I}-T_{R}\right)
$$

where

$C_{p, L}=$ the specific heat capacity of water $\left(1 \mathrm{cal} /\left(\mathrm{g}{ }^{\circ} \mathrm{C}\right)\right)$

$m_{w F}=$ final mass of water in bath after vapor delivery $(\mathrm{g})$

$m_{w I}=$ initial mass of water in bath before vapor delivery $(\mathrm{g})$

$m_{w R}=$ mass of water removed from bath due to the fixture assembly (g)

$T_{F}=$ final temperature of water in bath after vapor delivery $\left({ }^{\circ} \mathrm{C}\right)$

$T_{I}=$ initial temperature of water before vapor delivery $\left({ }^{\circ} \mathrm{C}\right)$
$T_{R}=$ reference temperature $\left(37^{\circ} \mathrm{C}\right)$

The increase in energy of the water bath after the vapor delivery (left side of equation 2) is equal to the energy decrease of the vapor. The energy of the vapor is comprised of sensible heat (1st term on the right) and latent heat (2nd term on the right).

$$
\begin{aligned}
& \left(m_{w F}+m_{w R}\right) \cdot C_{p, L}\left(T_{F}-T_{R}\right)-m_{w l} \cdot C_{p, L}\left(T_{I}-T_{R}\right)= \\
& \Delta m \cdot C_{p, L} \cdot\left(T_{100}-T_{R}\right)+\Delta m \cdot \frac{m_{G}}{\Delta m} \cdot \bar{H}_{v}(100)
\end{aligned}
$$

This energy balance can be used to derive the fraction of the delivered vapor mass that is gaseous:

$$
\frac{m_{G}}{\Delta m}=\frac{\frac{T E}{\Delta m}-C_{p, L} \cdot\left(T_{100}-T_{R}\right)}{\bar{H}_{v}(100)}
$$

where

$m_{G}=$ mass of gaseous water delivered during the vapor treatment $(\mathrm{g})$

$\Delta m=m_{L}+m_{G}=\left(m_{w F}-m_{w I}+m_{w R}\right)=$ mass of liquid and gaseous water delivered during the vapor delivery $(\mathrm{g})$

$T_{100}=$ boiling point of water at $1 \mathrm{~atm}\left(100^{\circ} \mathrm{C}\right)$

$\bar{H}_{v}(100)=$ the latent heat of vaporization of water at $1 \mathrm{~atm}$ and $100^{\circ} \mathrm{C}(539 \mathrm{cal} / \mathrm{g})$

The mass fraction can be used to calculate the amount of energy attributable to the gaseous portion of the vapor. This is called the $\mathrm{VE}$ and is calculated in calories:

$$
V E=\Delta m \cdot \frac{m_{G}}{\Delta m} \cdot\left(\bar{H}_{v}(100)+C_{p, L} \cdot\left(T_{100}-T_{R}\right)\right)
$$

All clinical vapor treatment times are limited to the range 3-10 s. The limits of this range are used to test and characterize vapor generators. A characteristic curve relating energy to time can be defined once the energy output is characterized at 3, 7 and $10 \mathrm{~s}$. This characteristic curve is used to calculate treatment times for all segment sizes (measured in grams).

For the clinical trial system, characteristic curves were created for each generator. Each patient treatment program was calculated using a curve specific to a generator. This reduced variability in energy output and was an acceptable method for clinical studies due to the level of control and the limited number of units. For the InterVapor system, design improvements were incorporated to reduce variability in energy output between generators. This permitted the use of a single characteristic curve for all generators.

\section{Thermal Distribution}

A lung model was designed to simulate thermal distribution of vapor treatments in human pulmonary tissue. Because assessing thermal distribution within the lung is not possible with tissue, a model was designed to simulate human lung airways and adjacent parenchyma. A material was identified that would react to the energy from an InterVapor treatment in a similar manner to the lung parenchyma: an open-celled sponge with cells of similar diameter to human alveoli [8-10]. A 5-generation airway tree was imbedded in between two sponges. The airway model was built from a heat-resistant rapid prototyping material. The dimensions were specified in order to be similar to actual anatomy $[11,12]$. A 
branch angle of $39^{\circ}$ was used as it is similar to what is found in humans, and it offered the optimal layout of the airways to prevent overlap and increase symmetry. A wall thickness of $0.7 \mathrm{~mm}$ was chosen because it is similar to in humans and it offers sufficient structural integrity. Five generations is the largest number of generations the model could have and still be adapted to lie in a 2-dimensional plane.

This lung model is advantageous because it is sensitive to many vapor application parameters including TE and VE. The model simulates a lung segment and allows vapor treatments to be delivered to it. Following treatment, the model is automatically split in half and an internal cross section of the lung segment is exposed to an infrared camera (fig. 1). The resultant image can be analyzed and the area above specified temperature thresholds can be calculated. Based on published time-temperature correlations and in vivo testing for tissue ablation, applied energy should have a minimum temperature between 50 and $70^{\circ} \mathrm{C}$ in order to achieve necrosis [13-17]. The minimum temperature required for ablation is dependent on the tissue typeand thickness and the duration of energy application. In addition, the exact differences between the model and clinical effect are not fully known, therefore a wide range of temperature thresholds are considered.

\section{Data Analysis}

TE and VE measurements of the vapor systems were compared with example calculations of TE and VE done for 3 example segments that spanned the range treated clinically. The segment sizes of 13, 26 and $42 \mathrm{~g}$ represent the small, medium and large masses treated clinically with the clinical trial system. For each segment size, the difference in TE (table 1) and VE (table 2) was calculated between the clinical trial system at $10.0 \mathrm{cal} / \mathrm{g}$ and the InterVapor system at 10.0, 8.5, 8.0 and $7.5 \mathrm{cal} / \mathrm{g}$. This calculation was repeated for all segments sizes in the range of $13-42 \mathrm{~g}$ in 1-gram intervals. The results were plotted (fig. 2) and the differences averaged (tables 3, 4).

Vapor was delivered to the lung model at three different energy levels spanning the range treated clinically. The clinical trial system at $10.0 \mathrm{cal} / \mathrm{g}$ and the InterVapor system at 10.0, 8.5, 8.0 and 7.5 $\mathrm{cal} / \mathrm{g}$ were tested. At least nine vapor deliveries and the resultant thermal profile measurement was done for each system and energy level combination. For each vapor delivery, the thermal profile was characterized by calculating the area of the sponge cross section that exceeded the temperature thresholds covering the range of $45-80^{\circ} \mathrm{C}$ in intervals of $5^{\circ} \mathrm{C}$; values within intervals were interpolated.

\section{Results}

\section{TE and VE Measurement}

Initial energy measurement analysis was done for 3 example segments sizes that spanned the range treated clinically. When the vapor dose upper limit was set to 10 $\mathrm{cal} / \mathrm{g}$, both the clinical trial and InterVapor systems delivered identical amounts of TE (table 1). However, the amount of energy contributed by gas (i.e. VE) was higher with the InterVapor system for each segment (table 2). When the vapor dose upper limit of the InterVapor sys-

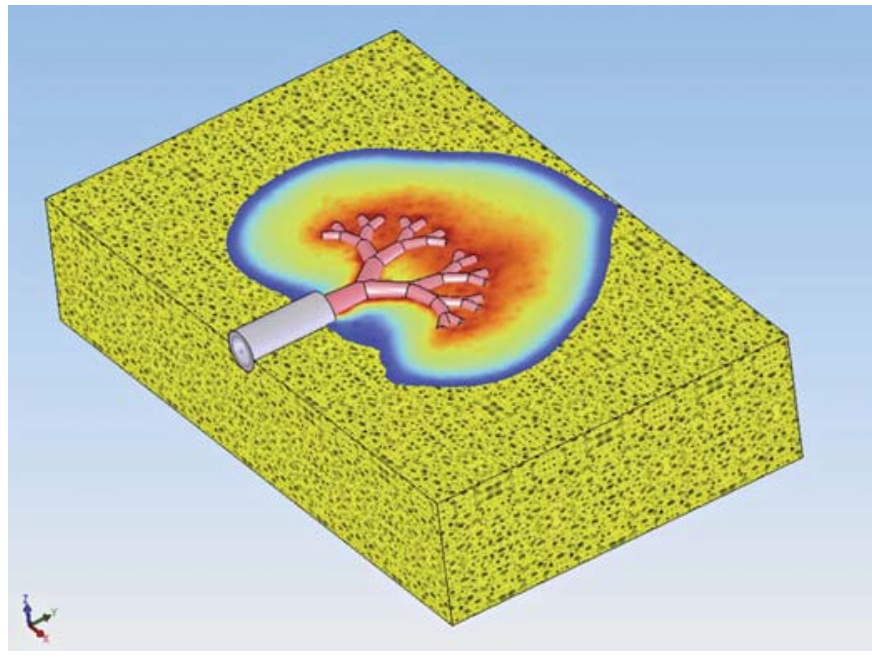

Fig. 1. An example infrared image of a thermal profile overlaid on a schematic of the lung model.

Table 1. Absolute differences in TE between vapor systems at 3 different example segment sizes

\begin{tabular}{lccccccc}
\hline & \multicolumn{3}{l}{ Absolute, cal } & & & \multicolumn{3}{l}{ Relative, \% } \\
\cline { 2 - 3 } & $\begin{array}{l}\text { small } \\
(13 \mathrm{~g})\end{array}$ & $\begin{array}{l}\text { medium } \\
(26 \mathrm{~g})\end{array}$ & $\begin{array}{l}\text { large } \\
(42 \mathrm{~g})\end{array}$ & & $\begin{array}{l}\text { small } \\
(13 \mathrm{~g})\end{array}$ & $\begin{array}{l}\text { medium } \\
(26 \mathrm{~g})\end{array}$ & $\begin{array}{l}\text { large } \\
(42 \mathrm{~g})\end{array}$ \\
\hline IV 10.0 & 0 & 0 & 0 & & 0 & 0 & 0 \\
IV 8.5 & -18 & -39 & -63 & & -15 & -15 & -15 \\
IV 8.0 & -24 & -52 & -84 & & -20 & -20 & -20 \\
IV 7.5 & -30 & -65 & -105 & & -25 & -25 & -25 \\
\hline
\end{tabular}

TE of the clinical trial system at $10.0 \mathrm{cal} / \mathrm{g}$ was subtracted from the TE of the InterVapor system (IV) at 10.0, 8.5, 8.0 and $7.5 \mathrm{cal} / \mathrm{g}$.

Table 2. Absolute differences in VE between vapor systems at 3 different example segment sizes

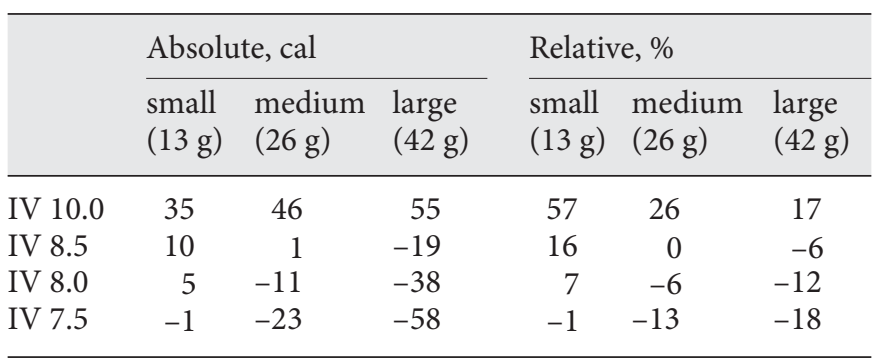

TE of the clinical trial system at $10.0 \mathrm{cal} / \mathrm{g}$ was subtracted from the TE of the InterVapor system (IV) at 10.0, 8.5, 8.0 and $7.5 \mathrm{cal} / \mathrm{g}$. 


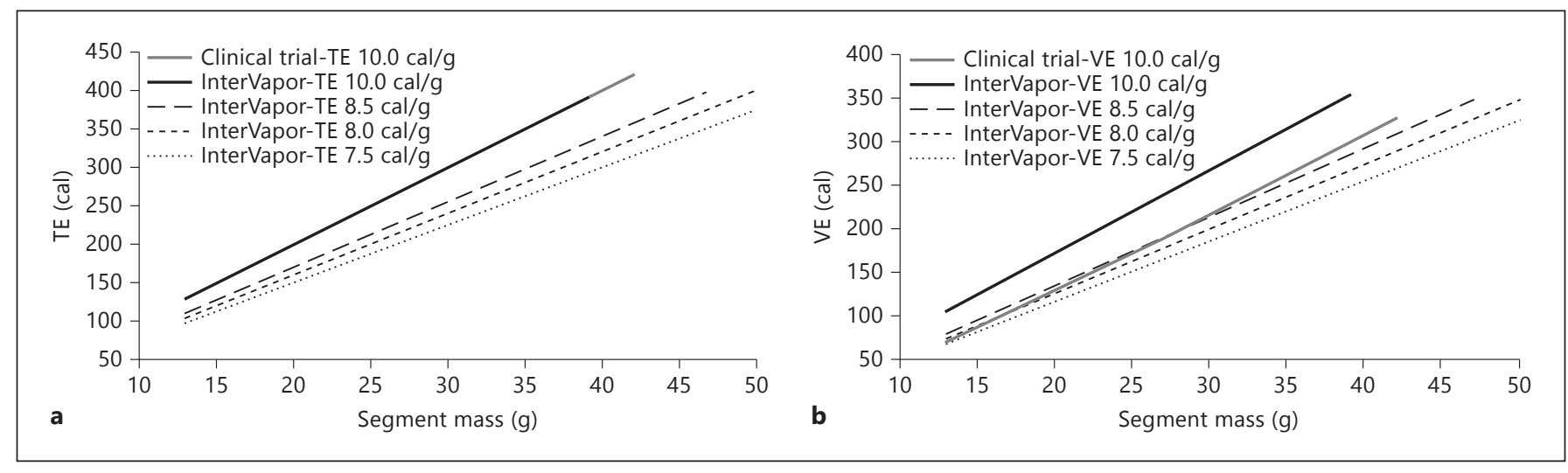

Fig. 2. Energy output from the clinical trial and InterVapor systems. a Total energy produced with the clinical trial system 10.0 $\mathrm{cal} / \mathrm{g}$ and InterVapor at 10.0, 8.5, 8.0 and $7.5 \mathrm{cal} / \mathrm{g}$ for a given segmental mass. The clinical trial and InterVapor system $10.0 \mathrm{cal} / \mathrm{g}$

Table 3. Mean differences in TE between vapor systems for all segments between 13 and $42 \mathrm{~g}$ in 1-gram intervals

\begin{tabular}{llllll}
\hline & \multicolumn{2}{l}{ Absolute, cal } & & \multicolumn{2}{l}{ Relative, \% } \\
\cline { 2 - 3 } \cline { 5 - 6 } & $\begin{array}{l}\text { mean } \\
\text { difference }\end{array}$ & $\begin{array}{l}\text { standard } \\
\text { error }\end{array}$ & & $\begin{array}{l}\text { mean } \\
\text { difference }\end{array}$ & $\begin{array}{l}\text { standard } \\
\text { error }\end{array}$ \\
\hline IV 10.0 & 0 & 0 & & 0 & 0.0 \\
IV 8.5 & -41 & 2.4 & & -15 & 0.0 \\
IV 8.0 & -55 & 3.2 & & -20 & 0.0 \\
IV 7.5 & -69 & 4.0 & & -25 & 0.0 \\
\hline
\end{tabular}

TE of the clinical trial system at $10.0 \mathrm{cal} / \mathrm{g}$ was subtracted from the TE of the InterVapor system (IV) at 10.0, 8.5, 8.0 and $7.5 \mathrm{cal} / \mathrm{g}$ for each segment and then averaged.

tem was set to $8.5 \mathrm{cal} / \mathrm{g}$, the comparability of the VE between the systems was improved across the range of segment sizes.

In order to further evaluate the optimal selection of a vapor dose upper limit based on TE and VE rather than on TE alone, the energy required (TE and VE independently) for each dose was calculated in 1-gram increments from 13 to $42 \mathrm{~g}$. The means of the differences between the two systems at each dose considered are summarized in tables 3 and 4 . The analysis provides a concise approach to compare the various doses to select the dose that is most closely aligned in $\mathrm{VE}$ while minimizing the associated reduction in TE. InterVapor at $8.5 \mathrm{cal} / \mathrm{g}$ appears to be most similar to the VE produced by the clinical trial system at the $10.0 \mathrm{cal} / \mathrm{g}$ upper limit while minimizing the reduction in TE. lines overlap. b Vapor energy produced with the clinical trial system $10.0 \mathrm{cal} / \mathrm{g}$ and InterVapor system at $10.0,8.5,8.0$ and $7.5 \mathrm{cal} / \mathrm{g}$ for a given segmental mass.

Table 4. Mean differences in VE between vapor systems for all segments between 13 and $42 \mathrm{~g}$ in 1-gram intervals

\begin{tabular}{llllll}
\hline & \multicolumn{2}{l}{ Absolute, cal } & & \multicolumn{2}{l}{ Relative, \% } \\
\cline { 2 - 3 } \cline { 5 - 6 } \cline { 5 - 6 } & $\begin{array}{l}\text { mean } \\
\text { difference }\end{array}$ & $\begin{array}{l}\text { standard } \\
\text { error }\end{array}$ & & $\begin{array}{l}\text { mean } \\
\text { difference }\end{array}$ & $\begin{array}{l}\text { standard } \\
\text { error }\end{array}$ \\
\hline IV 10.0 & 47 & 1.1 & & 27 & 1.7 \\
IV 8.5 & -2 & 1.6 & & 1 & 1.0 \\
IV 8.0 & -15 & 2.3 & & -6 & 0.8 \\
IV 7.5 & -28 & 3.1 & -13 & 0.7 \\
\hline
\end{tabular}

TE of the clinical trial system at $10.0 \mathrm{cal} / \mathrm{g}$ was subtracted from the TE of the InterVapor system (IV) at 10.0, 8.5, 8.0 and $7.5 \mathrm{cal} / \mathrm{g}$ for each segment and then averaged.

The values from the energy calculations based on 1 -gram increments are plotted in figure $2 \mathrm{a}$ and $\mathrm{b}$. Graphing the calculated energy produced by the above vapor doses for both systems provides a visual representation that highlights the differences in TE and VE. The graphical representation of energy indicates that VE from InterVapor $8.5 \mathrm{cal} / \mathrm{g}$ is the most like that of the clinical trial system at $10.0 \mathrm{cal} / \mathrm{g}$ with the smallest reduction in TE relative to the clinical trial system $10.0 \mathrm{cal} / \mathrm{g}$.

\section{Thermal Threshold}

The results from the lung model are summarized in figure 3. In the study, a range of energy levels (low: approx. $3 \mathrm{~s}$, medium: approx. $7 \mathrm{~s}$ and high: approx. $10 \mathrm{~s})$ and a range of thermal thresholds $\left(45-80^{\circ} \mathrm{C}\right.$ in $5^{\circ} \mathrm{C}$ intervals) were considered. Treatment times were calculated based 
on theoretical segment sizes of 12, 26 and $38 \mathrm{~g}$. At each energy level and threshold, the cross-sectional area of the model that reached the threshold temperature was measured to characterize the thermal distribution. In no comparison between systems was it possible to show the thermal distribution of the InterVapor system at 8.5, 8.0 and $7.5 \mathrm{cal} / \mathrm{g}$ to be greater than the thermal distribution of the clinical trial system $(10.0 \mathrm{cal} / \mathrm{g})$. Thermal distribution characterization of InterVapor at $10.0 \mathrm{cal} / \mathrm{g}$ was performed during a separate study, but was included for comparison purposes. All data in this study were collected between January and June of 2012 .

\section{Discussion}

Thermal energy has been used therapeutically for decades. Application of the energy is dependent on the physics and properties of the system used to transfer it (i.e. microwaves, radiofrequency, laser and water vapor). The use of thermal energy delivered via heated water vapor to the lung in patients with emphysema to induce lung volume reduction through tissue ablation is a relatively recent application and has been based on the TE delivered, a mix of the energy contained in gas and liquid [2-5]. The dose of energy has been evaluated in several clinical trials to determine an optimal application dose that is efficacious with an acceptable safety profile. Improvement in the InterVapor system compared to the clinical trial system has been accompanied by a detailed evaluation of energy delivery to optimize the equivalence of the 2 systems. As a result, the range for the TE dose delivered can be narrowed with a lower upper limit while delivering similar amounts of effective energy. In addition, the improved understanding of TE and VE may contribute to the development of future clinical vapor dosing applications.

Several issues need to be considered in the evaluation of the therapeutic application of thermal energy. Such issues include the vehicle for delivering the energy (i.e. radiofrequency, microwaves, laser or vapor), the energy rate and composition, the dose range and the testing methodology to evaluate the energy delivery. Energy from the InterVapor system is transmitted via heated water vapor. The clinical advantage of vapor over other modalities is the ability to transmit large amounts of energy quickly and over a distance ( $1 \mathrm{~g}$ of water in the gaseous state is capable of delivering 602 calories of energy to tissue). This unique capability allows for a more precise and controlled energy delivery compared to other modalities.
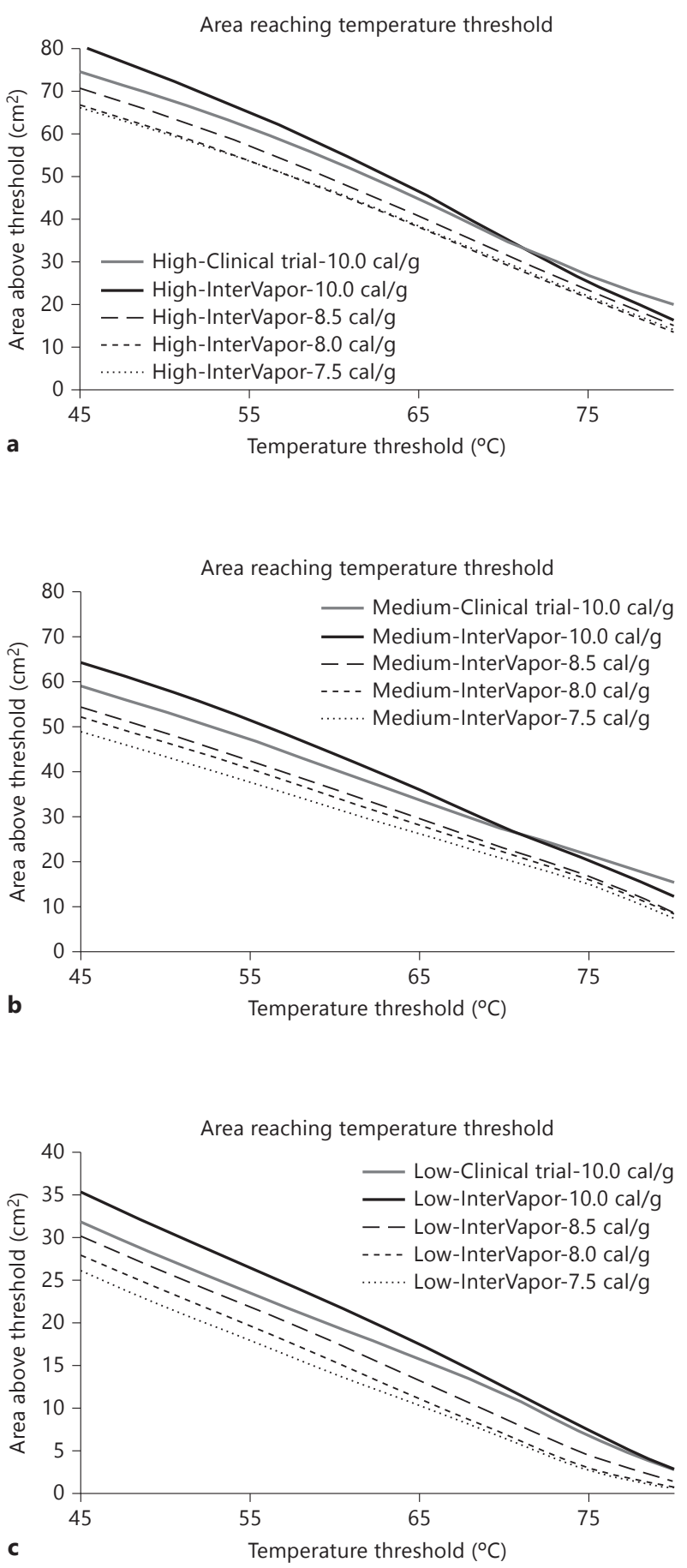

Fig. 3. Plot of area above temperature threshold versus temperature threshold for the clinical trial and InterVapor systems at a high energy level (approx. $10 \mathrm{~s}$ ) (a), a medium energy level (approx. 7 s) (b) and a low energy level (approx. 3 s) (c). 
Vapor dosing for lung volume reduction is calculated as the TE per gram of tissue targeted for treatment. This dose has units of $\mathrm{cal} / \mathrm{g}$. The precise energy delivery is individualized based on a quantitative high resolution computed tomography (HRCT) of the lung for mass. The mass is used to calculate the required TE of heated water vapor for the specified dose.

Due to differences in anatomy and mass within a segment or subsegment, a range of dosing is needed in order to ensure treatment of the full targeted area within a lobe. Preclinical studies have demonstrated that a fibrotic response can be provoked after administration of TE in the dose range of 7.5-10.0 cal/g of tissue [5]. Clinical studies have indicated that a TE dose in the aforementioned range is safe and efficacious. A 1-year study of the endoscopic delivery of vapor for tissue ablation in emphysema indicated that TE doses of up to $10.0 \mathrm{cal} / \mathrm{g}$ resulted in significant improvements in airflow, hyperinflation, dyspnea and healthrelated quality of life with an acceptable safety profile [2-4], including patients with incomplete fissures [18]. The mechanism of action is through inflammation leading to contraction fibrosis. The localized inflammatory process may result in an increase in respiratory symptoms that may require intervention. Once the lung heals, there are no devicerelated long-term effects as there are no chemicals or devices left behind. Following clinical studies, the objectives of continuous improvement in a next-generation system (referred to as InterVapor) were to improve the consistency of energy delivery, usability and manufacturability.

While the measured TE released per treatment is important and has a target range, additional evaluations have been conducted that consider only the VE component of the TE. The water bath measurement of TE between the clinical trial system at the $10.0 \mathrm{cal} / \mathrm{g}$ upper dose limit and the InterVapor system at the $10.0 \mathrm{cal} / \mathrm{g}$ upper dose limit confirmed that the systems had equivalent outputs and that the InterVapor system was associated with reduced variability. Further detailed studies, specific to $\mathrm{VE}$, indicated that the InterVapor system output at 10.0 $\mathrm{cal} / \mathrm{g}$ was higher than the clinical trial system at $10.0 \mathrm{cal} / \mathrm{g}$, presumably due to improvements in the system that improved the consistency and reduced the proportion of energy released in liquid droplet form from the catheter tip. Subsequent testing of the InterVapor system at 3 different doses showed $8.5 \mathrm{cal} / \mathrm{g}$ to be the dose with VE most similar to the clinical trial system at the $10.0 \mathrm{cal} / \mathrm{g}$ upper limit while minimizing the reduction in TE.

Support for this conclusion was obtained from the lung model that compared the thermal distribution of the clinical trial system at the $10.0 \mathrm{cal} / \mathrm{g}$ upper dose limit and InterVapor at the 8.5, 8.0 and $7.5 \mathrm{cal} / \mathrm{g}$ upper dose limits. The lung model compared the thermal distribution across a range of temperature thresholds. At each threshold evaluated, the thermal distribution of the InterVapor system was not greater than that of the clinical trial system. The sensitivity to change at relatively small differences in dosing provides data indicative of the robustness and validity of the model. The results support the observations from the water bath energy measurements and the conclusion that InterVapor $8.5 \mathrm{cal} / \mathrm{g}$ upper dose limit is the optimal dose in that the VE is closest to the VE of the clinical trial system at the upper limit of $10.0 \mathrm{cal} / \mathrm{g}$.

In summary, increased comparability in VE between the InterVapor and clinical trial system was achieved by tightening the vapor dose range (TE) from 10.0-7.5 to $8.5-7.5 \mathrm{cal} / \mathrm{g}$, while remaining within the original specified range. The InterVapor upper limit dose produces VE that is most similar to the clinical trial system at 10.0 $\mathrm{cal} / \mathrm{g}$ while having the smallest effect (reduction) on TE. The results of the lung model provide supportive information for this vapor dose upper limit in that the thermal distribution is similar to, yet does not exceed, the distribution created by the clinical trial system. The improved consistency of the system is anticipated to provide increased reliability of anticipated efficacy while presumably reducing the risk of adverse effects. Long-term clinical follow-up in large populations of patients with emphysema can provide additional confirmation of the positive clinical implications of the bench studies. Currently, thermal energy is being used or is in development for other pulmonary diseases (e.g. cancer and asthma) and for nonpulmonary disorders (e.g. uterine disease, prostate disease and varicose veins). The approach and observations in this study will need to be considered during development of vapor dosing for other clinical applications.

\section{Acknowledgements}

We wish to gratefully acknowledge the contributions of Daniel Reddy and Josh Kroon who assisted with testing and data collection.

\section{Disclosure Statement and Conflicts of Interest}

E.H. and S.K. are employees of Uptake Medical. F.J.F.H. is on the Uptake Medical Scientific Advisory Board and has received an honorarium from Uptake Medical for participation in educational symposia. 


\section{References}

1 Gasparini S, Zuccatosta L, Bonifazi M, et al: Bronchoscopic treatment of emphysema: state of the art. Respiration 2012;84:250263.

-2 Snell GI, Hopkins P, Westall G, et al: A feasibility and safety study of bronchoscopic thermal vapor ablation: a novel emphysema therapy. Ann Thorac Surg 2009;88:1993-1998.

-3 Snell G, Herth FJ, Hopkins P, et al: Bronchoscopic thermal vapor ablation therapy in the management of heterogeneous emphysema. Eur Resp J 2012;39:1326-1333.

4 Herth FJF, Ernst A, Baker KM, et al: Characterization of outcomes one year after endoscopic thermal vapor ablation for patients with heterogeneous emphysema. Int J COPD 2012;2:397-405.

$>5$ Tuck SA, Lopes-Berkas V, Beam S, et al: Bronchoscopic thermal vapor ablation in a canine model of emphysema. Int J COPD 2012;7:2131.

-6 Haines P: Principles of Thermal Analysis and Calorimetry. Cambridge, Royal Society of Chemistry, 2002.
7 Incropera F, DeWitt D: Introduction to Heat Transfer, ed 4. New York, Wiley, 2001.

8 Albertine KH, Williams MC, Hyde DM: Textbook of Respiratory Medicine, ed 3. Murray JF, Nadel JA (eds). Philadelphia, WB Saunders, 2000.

9 West JB: Pulmonary Pathophysiology, ed 7. Baltimore, Lippincott Williams \& Wilkins, 2008.

10 West JB: Respiratory Physiology, ed 7. Baltimore, Lippincott Williams \& Wilkins, 2005.

11 Sauret V: Study of the three-dimensional geometry of the central conducting airways in man using computed tomographic (CT) images. J Anat 2002;200:123-134.

12 Weibel ER: Morphometry of the Human Lung. New York, Academic Press, 1963.

13 Bunch TJ, Bruce GK, Johnson SB, et al: Analysis of catheter-tip (8-mm) and actual tissue temperatures achieved during radiofrequency ablation at the orifice of the pulmonary vein. Circulation 2004;110:2988-2995.
Danek CJ, Lombard CM, Dungworth DL, et al: Reduction in airway hyperresponsiveness to methacholine by the application of RF energy in dogs. J Appl Physiol 2004;97:1946-1953.

15 Liu J, Chen X, Xu LX: New thermal wave aspects on burn evaluation of skin subjected to instantaneous heating. IEEE Trans Biomed Eng 1999;46:420-428.

-16 Nilsson B, Chen X, Pehrson S, Svendsen JH The effectiveness of a high output/short duration radiofrequency current application technique in segmental pulmonary vein isolation for atrial fibrillation. Europace 2006;8:962965.

17 van Nimwegen SA, L'Eplattenier HF, Rem AI, et al: Nd:YAG surgical laser effects in canine prostate tissue: temperature and damage distribution. Phys Med Biol 2009;54:29-44.

18 Gompelmann D, Heussel CP, Eberhart R, et al: Efficacy of bronchoscopic thermal vapor ablation and lobar fissure completeness in patients with heterogeneous emphysema. Respiration 2012;83:400-406. 